\title{
Sue Matthews, Winner 2011 Margret Comack Award for Nursing Leadership
}

During HealthAchieve 2011, Sue Matthews, Interim President and CEO of the Niagara Health System, recently received the 2011 Margaret Comack Award of Excellence in Nursing Leadership. This award acknowledges the outstanding leadership of an individual nurse who holds a senior position in a member organization of the Ontario Hospital Association.

\section{Q: What have you found to be the most} important attributes for leadership? Why? A: Leadership is not one-dimensional, but rather is reflected through systems thinking in multidimensional ways. Leadership involves both tangible skills and personality.

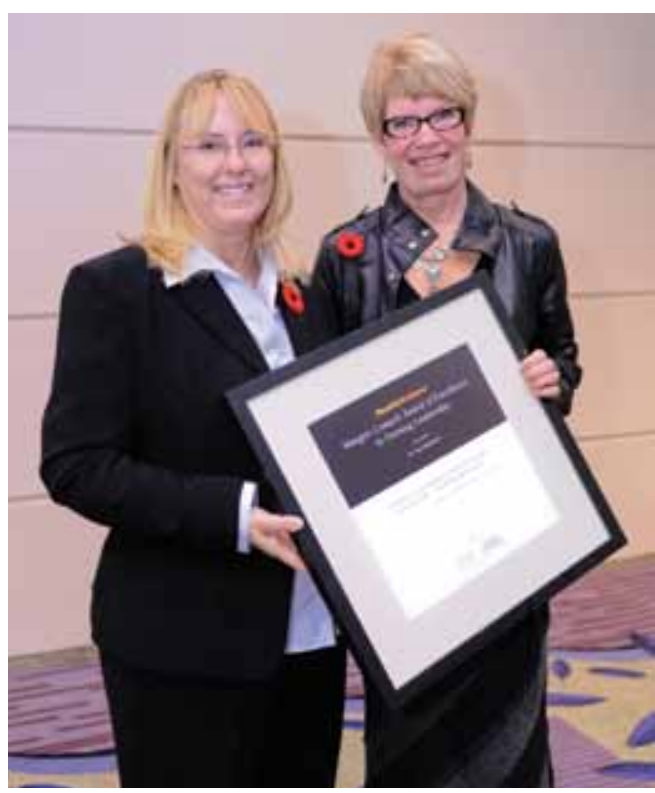

Sue Matthews (left) with Margret Comack

I believe that in order to achieve excellence, one must first be a leader of good character. That character develops over time. It is not necessarily something you are born with. Each experience you encounter builds your personal character. The constant change and immense pressures facing those in healthcare require us to be particularly strong. Throughout every experience, I believe that leaders must be authentic. As an authentic individual, one is open to others and thus allows them to be open and show their own true self. This is important because of the chaos we work in across the healthcare environment. An authentic leader 
"models the way," acting as a role model - setting the example for others. A further attribute I believe in strongly is integrity. A leader who acts with integrity adheres to a code of conduct and code of ethics and has an underlying system of values that is manifested in his or her behaviour. I believe this must be evident to all and must be consistently applied in everything we do.

Finally, I would be remiss if I didn't say that humour is also necessary in a leader. When used appropriately, humour can put others at ease, can defuse a difficult or uncomfortable situation, can show that you are authentic and can increase morale. When groups of people laugh together, it builds a camaraderie or special bond among them, which is very powerful.

\section{Q: How would you describe your leadership style? Has it evolved over your career, and if so, what were the most important influences?}

A: My leadership style has been described by others as "transformational." My doctoral research was on empowerment, and I believe strongly in empowering others to achieve their goals, whether they are personal or professional. The use of Kanter's theory of empowerment has allowed me to understand that empowerment is not just an action - "I empower thee" - but rather a specific theory and process. It must be purposeful and with intent. Empowered individuals and groups must be given the tools to make the decisions or take the actions they are empowered to do. I believe firmly in ensuring that my leadership style continues to empower others. I think that with experience comes confidence, so my style has definitely evolved over time. As I have tried certain things and evaluated their success, I have used methods that have been successful more frequently. In addition to this, as I got more feedback about my leadership, I have used that feedback to evolve.

Several things have influenced my leadership style. First and foremost, I have been blessed to have had wonderful mentors who "modelled the way" for me. In observing their actions, integrity and authenticity, I was able to understand how powerful these attributes are. I believe strongly in "followership" and know that in order to be a good leader, one must also be a good follower. My personal evolution of leadership has stemmed from learning to be a good follower as much as it has learning to be a good leader.

\section{Q: What is the most satisfying aspect of your role as a nurse leader? What has been the most disappointing?}

A: The most satisfying thing for me has been seeing those that I have mentored grow into successful leaders themselves. I have greatly enjoyed watching others evolve and knowing that I played some role in their growth. I believe that mentorship is a circle. As I have learned from others, I believe that it is my responsibility 
to fulfill the circle to be a mentor to others. I also believe that one's personal success can be fulfilled only through the success of others. Thomas Jefferson said, "I hope our wisdom will grow with our power, and teach us that the less we use our power the greater it will be."

The most disappointing is difficult, as I believe that the best learning comes from the toughest times and through your biggest mistakes. So, every experience, good and bad, plays a role in your own personal growth. It has been said that leaders don't command excellence, they build it.

I do continue to be disappointed by the overwhelming preoccupation of the public and politicians with acute care. While acute care is essential, I believe the lack of evolution of primary care, health promotion and disease prevention is at the heart of the healthcare challenges we face. I believe we do know the solutions, but have essentially been unable to design policy that supports this necessary fundamental shift to a health system that focuses on upstream prevention rather than illness focus and cure.

\section{Q: What do you consider to be the most significant challenge facing nurse leaders over the next few years?}

A: I believe that the next three to five years will bring challenges for nurse leaders that we can't even predict. We are all aware of the economic crisis, which has brought and will continue to bring a need to address real financial challenges. With these challenges comes a pressure to address the issues using the same approaches used in the 1990s, such as massive lay-offs and cuts to nursing. The economic crisis is leading to decreased funding for healthcare, and nurse leaders need to use the evidence that we have to show the impacts of the potential decisions we are challenged or pressured to make. We must resist the temptation to address the issues through the same mistakes that were made. As nurse leaders, we must be able to articulate the evidence in a language that can be understood by our audience. As a nurse leader [myself, I can say that] speaking many languages is key. Nurse leaders must speak the languages of finance, outcomes and accountability. With legislation requiring chief nurse executives to sit on the board of public hospitals, we have a unique opportunity to influence decisions through our seat at the table. We must use this place wisely and present our case from the patients' perspective, showing decision-makers the implications of options being considered.

Healthcare leaders are under immense scrutiny, which is increasing. Public concerns over the quality of healthcare have led to increased performance monitoring and accountability requirements. These will provide additional challenges for nursing leaders. However, I believe that these also bring opportunity. As nurses, we are used to measuring the outcomes of our care, and I believe that 
measuring the outcomes of all of our decisions is a good thing. Public accountability will add a level of transparency to decision-making, and nurses are uniquely positioned to show the difference nursing makes in ensuring healthy outcomes for those we serve.

\section{Q: What role do you see for nurse leaders in advancing transformation of the healthcare system over the next five years?}

A: Nurses are uniquely positioned to play a significant role in, and indeed lead, healthcare reform. Nurses provide care and leadership in all healthcare sectors. Our ability to understand the system from both a practitioner and patient perspective allows us to both understand and articulate the impacts of proposed changes. I believe that nurse leaders must advocate for a healthcare system that fosters health promotion and disease prevention. As nurses, we must ensure we always start from the patient/client/resident perspective - it's what nurses do best. Using this approach, we can't go wrong. It is difficult for decision-makers to argue with what's right for the patient/client/resident. When we do this, we are welcomed to the table, and I believe we will have great influence over transformation.

I believe that nurses must lead healthcare transformation. More and more nurses are in senior executive roles, such as provincial nursing advisers, CNEs at the board table or CEOs leading organizations. In these roles, we are well positioned to be the leaders of this reform.

\section{Q: What was the best piece of advice you were ever given in your career? Why?}

A: My dad told me, "Never take no from the person who can't tell you yes." He knew there would always be naysayers telling me I couldn't do something. He told me not to listen to them, and by heeding his advice, I have been able to tune out the negativity and focus on the positive and what I can do, instead of what I can't do. By tuning out the negative, you can ensure that no good idea is turned down before it has a chance.

A second piece of advice I received was from my husband. His advice was, "Never turn down a job you haven't been offered." His intent was to open me up to all possibilities. There were several jobs I have held that if I had listened to the voice in my head, I might not have applied for, thinking I wouldn't get the job, or that I couldn't do it. For example, as a front-line manager, I felt the need to stay close to my roots of clinical practice, wanting to stay as a manager on a surgical unit. However, when they offered me a job as a manager on a general medical unit, I wanted to turn it down, feeling that I would be too far out of my frame of reference and knowledge level. I did take the position, and in hindsight, the position I got immediately after this manager role was offered to me only because of my varied level of experience in both medicine and surgery. 
Additionally, two of the jobs I have held in my career didn't even exist when I started the job I held before it! For example, when I became a director in one hospital, the role of professional practice didn't exist, and my next position was as director of professional practice. Healthcare continues to evolve and change, and you must always be open to new thinking.

\section{Q: What piece of advice would you like to pass along to aspiring leaders?}

A: I would certainly use my Dad's advice and say, "Don't take no from the person who can't tell you yes."

Additionally, I would say that lifelong learning is a critical component of being a nurse. Healthcare knowledge is constantly changing, and nurses must participate in every learning opportunity we can in order to ensure we are seen as key players in any discussions about healthcare transformation. However, I would also advise that nurses and all healthcare professionals should read outside the healthcare literature. We have much to learn from other sectors, and can apply much of those learnings to healthcare.

I believe that as nurses, we used to gain knowledge. We were expected to "know everything," and we expected this of ourselves. With the speed of information [today], we now access knowledge rather than gain it. Nurses must know how to find information rather than hold it all in their minds.

Furthermore, nurses in all roles as leaders must ensure that we focus on the results or outcomes of what we do. In a society focused on outcomes, performance and accountability, we must ensure that we can measure the difference we make and the outcomes we achieve.

My final piece of advice is taken from and built upon a Canadian Nurses Association slogan from years ago (adding the word "leadership"): "Never, ever, ever let anyone tell you it'll be easy, just worth it... nursing leadership.”

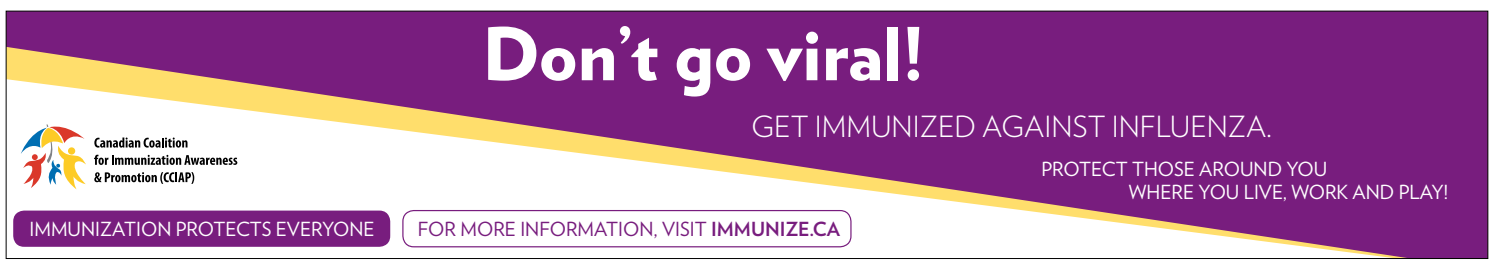

